\title{
The Prevalence of Attention Deficit Hyperactivity Symptoms in Schoolchildren in a Highly Consanguineous Community
}

\author{
Abdulbari Bener ${ }^{a}$ e Razna Al Qahtani ${ }^{c}$ Ahmad S. Teebi ${ }^{d, f}$ \\ Mohammed Bessisso ${ }^{b}$
}

${ }^{a}$ Department of Medical Statistics and Epidemiology and ${ }^{b}$ Department of Paediatric Neurology, Hamad General Hospital, and ' Department of Health Sciences, University of Qatar, Hamad Medical Corporation, and ${ }^{\mathrm{d}}$ Department of Pediatrics and Genetics Medicine, Weill Cornell Medical College, Doha, State of Qatar; eDepartment of Evidence for Population Health, School of Epidemiology and Health Sciences, University of Manchester, Manchester, UK; ' Division of Clinical and Metabolic Genetics, Hospital for Sick Children,

Toronto, Ont., Canada

\section{Key Words}

Hyperactivity, prevalence $\cdot$ Consanguinity $\cdot$ Behaviour •

Schoolchildren • Qatar

\begin{abstract}
Objective: The objective of the present study was to find the prevalence of attention deficit hyperactivity (ADH) symptoms in a sample of primary schoolchildren in Qatar and investigate the behaviour of the children with and without ADH symptoms in a highly consanguineous community. Subjects and Methods: A total of 2,500 primary school students, aged 6-12 years, were randomly selected from the government primary schools, and 1,869 students (947 boys and 922 girls) gave consent to participate in this study. An Arabic questionnaire was used to collect the sociodemographic variables and a standardized Arabic version of the Conners' Teacher Rating Scale for ADH symptoms. Results: Of the 947 boys, 158 (16.7\%; 95\% confidence interval, Cl, 14.4-19.2) and of the 922 girls, $50(5.4 \% ; 95 \%$ Cl 4.1-7.1) scored above the cut-off $(\geq 15)$ for ADH symptoms, thus giving an
\end{abstract}

overall prevalence of $11.1 \%$ (95\% Cl 9.7-12.6). The children who had higher scores for ADH symptoms were in the age group of 6-9 years. Children who had higher scores for ADH symptoms had a poorer school performance than those with lower scores $(p=0.002)$. Two hundred $(96.2 \%)$ children with ADH were disobedient, 126 (60.6\%) noisy and hyperactive, 76 (36.5\%) very cranky, 78 (37.5\%) troublesome and 79 (37.9\%) nervous. The logistic regression identified socio-economic condition, number of children, school performance and poor relationship between parents as the main contributors to $A D H$. Although the univariate analysis showed a significant relationship ( $p=0.010$ ) between ADH symptoms and consanguineous parents, logistic regression did not support this association $(p=0.075)$. This suggests that consanguinity has no impact on ADH children. Conclusion: The study revealed that ADH is a common problem among schoolchildren. The children with higher scores for ADH symptoms had a poorer school performance than those with lower scores. A significant difference exists between the behaviour of children with and without ADH.

Copyright $\odot 2008$ S. Karger AG, Basel

\section{KARGER}

Fax +4161306 1234

E-Mail karger@karger.ch

www.karger.com (c) 2008 S. Karger AG, Basel

$1011-7571 / 08 / 0176-0440 \$ 24.50 / 0$

Accessible online at:

www.karger.com/mpp
Prof. Abdulbari Bener, Advisor to WHO

Department of Medical Statistics and Epidemiology, Hamad General Hospital

Hamad Medical Corporation and Weill Cornell Medical College Qatar

PO Box 3050, Doha (State of Qatar)

Tel. +974 439 3765, Fax +974 439 3769, E-Mail abener@hmc.org.qa 


\section{Introduction}

During the last few decades, many reports have raised concern about childhood hyperactivity and inattentiveness [1]. Attention deficit hyperactivity (ADH) disorder may affect all aspects of a child's life. ADH is a common disorder in school age children [2]. It is one of the leading causes of academic underachievement in school as well as disruptive behaviours. The symptoms of ADH are caused by a neurological dysfunction within the brain, and the underlying physiological mechanism which causes $\mathrm{ADH}$ is still not thoroughly understood and remains under scientific study [3]. There is limited information about this phenomenon among non-western cultures, in particular in the Arab region [4].

Qatar has one of the highest rates of consanguinity (54\%) in the world with $34.8 \%$ of marriages between first cousins and $13.4 \%$ between those related more distantly. It was important to identify whether the high prevalence rate of $\mathrm{ADH}$ in children could be related to the highly consanguineous community [5]. During the last decade, evidence has accumulated indicating that symptoms of $\mathrm{ADH}$ persist into adulthood in $30-70 \%$ of children diagnosed as having the disorder [6,7]. Children with ADH may have functional impairment across multiple settings including home, school and social relationships. ADH has also been shown to have long-term adverse effects on academic performance, vocational success and socialemotional development [3]. Among children, ADH is associated with an increased risk for accidents [8]. As they grow older, children with untreated $\mathrm{ADH}$, in combination with conduct disorders, experience drug abuse, antisocial behaviour and injuries of all sorts. Prospective studies also indicate that children affected by ADH are at a high risk of developing co-morbid disorders as well as impaired social adjustment [9].

Epidemiological studies have yielded various rates of $\mathrm{ADH}$ symptoms ranging from 3.2 to $17 \%$ [10]. The potential difference in the prevalence of $\mathrm{ADH}$ in western and non-western countries is related to biological, cultural and family factors [11]. Also, the variation in prevalence rates is due to the difference in the diagnostic criteria. Conners' Teacher Rating Scale (CTRS) is a popular instrument in the study of childhood hyperactivity [12]. Hence, in this study, the CTRS was used to evaluate ADH symptoms. The CTRS was used because teachers may be more accurate in their judgements in ratings of schoolchildren with regard to hyperactive symptoms (conduct disorder or hyperactivity).

Consanguinity and ADH Disorder in Arab Children
The objective of the present study was to find the prevalence of ADH symptoms in a sample of primary schoolchildren and investigate the behaviour of the children with and without ADH symptoms in a highly consanguineous community.

\section{Subjects and Methods}

This cross-sectional study was conducted in the government primary schools in the State of Qatar where the curriculum of the schools has been upgraded to a higher standard according to the modern system. The survey was done among schoolchildren between 6 and 12 years of age during the period from October 2006 to January 2007 in order to ensure that each class teacher had enough time to know and observe the student's behaviour and his/her academic performance. An Arabic questionnaire was used to collect the sociodemographic variables such as age, gender, nationality, level of education, occupation of parents or behaviour of children, and it was completed by the parents of the students. The types of behaviours that were reported were obedience, noisiness, high activity, nervousness, crying for any reasons and creating problems. Another standardized Arabic version of the CTRS was used to evaluate ADH symptoms [8, 13-15]. This form of rating is done by a teacher rating scale to examine children's behaviour at school.

To secure a representative sample of the study population, the sampling plan was stratified with proportional allocation. Stratification allowed both urban and semi-urban areas to be proportionally represented. The list of names of government schools was obtained from the Office of the Director of General Education, Ministry of Education. Government schools were segregated according to the sexes. There were 45,000 children enrolled in 52 government primary schools for boys and girls that are located in 21 different districts of Qatar. To fulfil the objective of the current study, the estimated sample size was 2,500 students. From the total of schools, 8 boys' schools and 8 girls' schools were randomly selected. During the first stage, one school from each district was randomly selected, thus overcoming the so-called 'cluster effect'. Then the 16 schools were put in one pool, and the names were randomly selected. Similarly, the classrooms and schoolchildren were selected in the second and third stages using the same simple random sampling procedure, finally resulting in the selection of 2,500 students who were a true random sample of the study population. All students who were present in these selected classrooms were included in the study, provided that they met the inclusion criteria of this study. Out of 2,500 students approached, a total of 1,869 students gave their consent to participate in the study. This constituted $4.2 \%$ of all the governmental primaryschool children enrolled in Qatar during the study year of $2006 / 2007$. The gender distribution of the actual participants was 947 boys and 922 girls.

The CTRS was used to screen ADH symptoms among children. Teacher rating scales [14] are also an important part of the evaluation and diagnosis. They provide necessary information about the child in the school setting. The teacher also becomes a secondary source of judging the behaviour of the child relative to his/her peers [15]. The CTRS has been widely used in different cultures and languages, and its reliability and validity have been

Med Princ Pract 2008;17:440-446 441 
well established [12]. This report from Hong Kong showed a fairly high sensitivity and specificity. The survey instruments were tested on 100 randomly selected students in different schools and validated in this way in the United Arab Emirates and Qatar $[8,13]$.

The CTRS contains 10 items for each of which the teacher was asked to indicate the degree of applicability to the child being assessed and which were scored as follows: not at all $=0$; just a little $=1 ;$ much $=2$, and very much $=3$. For each child, we added the item-specific scores to obtain the total scores. As recommended, the maximum score was 30 and the minimum was 0 . If the score of the child was from 0 to 9 or from 10 to 14 , the child was classified as having mild or moderate ADH symptoms, respectively. The child who scored 15 or higher in the CTRS was considered to have a high score for ADH symptoms, which might reflect the presence of ADH disorder. The parents completed the second questionnaire which included the sociodemographic variables such as age, gender, nationality, level of education and occupation. The literate parent of the children completed the questionnaire. In cases where both parents were illiterate, the children were excluded. In this survey, mostly mothers (75\%) completed the questionnaire. Also, children from the same nuclear family were excluded. Thus, only one child per family participated in the study. Non-Qataris are expatriates working in Qatar, and they were mostly from Middle East and Far East Asian countries. NonQatari children from Arab countries only were included in the study. The relationship of the consanguineous parents was recorded. Consanguinity was defined as marriages between relatives, either first or second cousins.

Student's t test was used to ascertain the significance of differences between mean values of two continuous variables and confirmed by the non-parametric Mann-Whitney test. A $\chi^{2}$ analysis was performed to test for differences in the proportion of categorical variables between two or more groups. Kruskal-Wallis oneway analysis of variance was used for comparison of several group means. Multiple logistic regression analysis using the forward inclusion and backward deletion method was used to asses the relationship between dependent (ADH symptoms) and independent variables and to adjust for potential confounders and orders the importance of risk factors (determinant) for ADH. $\mathrm{p}<0.05$ was considered as the cut-off value for significance.

\section{Results}

The sociodemographic characteristics of the subjects are shown in table 1 . Of the 1,869 children, 1,138 (60.9\%) were Qataris. Of the fathers, 1,698 (90.9\%) were employed, while only $553(29.6 \%)$ mothers were employed. Of the fathers and mothers, 482 (29.6\%) and 604 (32.3\%) were illiterate, respectively. Half of the schoolchildren were from the middle socio-economic group (USD 1,370.00$2,740.00$ per month), followed by the children from the high-income group (>USD 2,740.00 per month).

The prevalences of $\mathrm{ADH}$ symptoms among the subjects by sociodemographic characteristics and school performance are given in table 2 . The data revealed that 158 (16.7\%) boys (95\% confidence interval, CI, 14.4-19.2) and 50 (5.4\%) girls (95\% CI 4.1-7.1) scored above the cutoff point of $\geq 15$ for $\mathrm{ADH}$ symptoms, thus giving an overall prevalence of $11.1 \%$ (95\% CI 9.7-12.6). The differences between the boys' and girls' scores were statistically significant $(\mathrm{p}<0.001)$. Children who had higher scores for $\mathrm{ADH}$ symptoms were in the age group 6-9 years (13.9\%) compared to those aged $10-12$ years $(9.2 \%)$, and the difference was statistically significant $(\mathrm{p}<0.001)$. Also there was a statistically significant difference between children scoring above and below the cut-offs in relation to age, gender, ethnicity, consanguinity and favourable relationship between parents $(\mathrm{p}<0.001)$. Two hundred and twenty-eight $(26.5 \%)$ of the consanguineous children had moderate and higher scores for $\mathrm{ADH}$ symptoms. Children who had higher scores for $\mathrm{ADH}$ symptoms were judged by teachers as having a poorer performance than those with lower scores $(\mathrm{p}=0.002)$.

The comparison of the behaviour of children with and without $\mathrm{ADH}$ is given in table 3. Among the behavioural patterns, $96.2 \%$ of the children with $\mathrm{ADH}$ were reported to be disobedient, $60.6 \%$ noisy and hyperactive, $36.5 \%$ very cranky, $37.5 \%$ troublesome and $37.9 \%$ nervous. The children without $\mathrm{ADH}$ were reported to have fewer behavioural problems than the children with ADH. There was a significant difference between children with and without $\mathrm{ADH}$ for disobedience, making noise and crying for anything; $p$ values ranged from 0.002 to 0.014 .

The logistic regression analysis to assess predictors for $\mathrm{ADH}$ is shown in table 4. The logistic regression identified socio-economic condition, number of children, school performance and poor relationship between parents as the main contributors to $\mathrm{ADH}$. Other variables like occupation of parents, educational level of parents, parity and consanguinity did not show any significant contribution to $\mathrm{ADH}$.

\section{Discussion}

The prevalence rate (11.1\%) of ADH in Qatar is within the range of $6.1-19.0 \%$ reported for the United Arab Emirates, the USA, the UK, Canada and China $[8,13,16]$. There is a significant variability of $\mathrm{ADH}$ prevalence estimates around the world, but higher rates of $10.8-19.0 \%$ are reported in western countries. The differences could be attributed to the methodologies used in these studies, thereby making it difficult to have an adequate comparison. It is true that the presence of symptoms does not 
Table 1. Sociodemographic characteristics of the studied subjects by gender

\begin{tabular}{|c|c|c|c|c|}
\hline \multirow[t]{2}{*}{ Variables } & \multicolumn{2}{|l|}{ Gender } & \multirow{2}{*}{$\begin{array}{l}\text { Total } \\
(\mathrm{n}=1,869)\end{array}$} & \multirow[t]{2}{*}{$\mathrm{p}$ value } \\
\hline & boys $(\mathrm{n}=947)$ & girls $(n=922)$ & & \\
\hline \multicolumn{5}{|l|}{ Age group } \\
\hline $6-9$ years & $381(40.2)$ & $381(41.3)$ & $762(40.8)$ & \multirow[t]{2}{*}{0.631} \\
\hline $10-12$ years & $566(59.8)$ & $541(58.7)$ & $1,107(59.2)$ & \\
\hline \multicolumn{5}{|l|}{ Nationality of student } \\
\hline Qatari & $558(58.9)$ & $580(62.9)$ & $1,138(60.9)$ & \multirow[t]{2}{*}{0.078} \\
\hline Non-Qatari/Arabs & $389(41.1)$ & $342(37.1)$ & $731(39.1)$ & \\
\hline \multicolumn{5}{|l|}{ Occupation of father } \\
\hline Teacher/officer & $381(40.2)$ & $437(47.4)$ & $818(43.8)$ & \multirow[t]{6}{*}{$<0.001$} \\
\hline Army/police & $58(6.1)$ & $87(9.4)$ & $145(7.8)$ & \\
\hline Professional/manager & $321(33.9)$ & $275(29.8)$ & $596(31.9)$ & \\
\hline Businessman & $55(5.8)$ & $59(6.4)$ & $114(6.1)$ & \\
\hline Handicraftsman & $18(1.9)$ & $7(0.8)$ & $25(1.3)$ & \\
\hline Not working & $114(12.0)$ & $57(6.2)$ & $171(9.1)$ & \\
\hline \multicolumn{5}{|l|}{ Occupation of mother } \\
\hline Housewife & $690(72.9)$ & $626(67.9)$ & $1,316(70.4)$ & \multirow[t]{6}{*}{$<0.001$} \\
\hline Teacher/officer & $174(18.4)$ & $243(26.4)$ & $417(22.3)$ & \\
\hline Businesswoman & $30(3.2)$ & $12(1.3)$ & $42(2.2)$ & \\
\hline Professional/manager & $22(2.3)$ & $21(2.3)$ & $43(2.3)$ & \\
\hline Army/police & $15(1.6)$ & $10(1.1)$ & $25(1.3)$ & \\
\hline Retired/manual work & $16(1.7)$ & $10(1.1)$ & $26(1.4)$ & \\
\hline \multicolumn{5}{|l|}{ Educational level of mother } \\
\hline Illiterate & $328(34.6)$ & $275(29.8)$ & $603(32.3)$ & \multirow{5}{*}{$<0.001$} \\
\hline Primary & $206(21.8)$ & $198(21.5)$ & $404(21.6)$ & \\
\hline Intermediate & $210(22.2)$ & $161(17.5)$ & $371(19.9)$ & \\
\hline Secondary & $76(8.0)$ & $201(21.8)$ & $277(14.8)$ & \\
\hline University and above & $127(13.4)$ & $87(9.4)$ & $214(11.4)$ & \\
\hline \multicolumn{5}{|l|}{ Educational level of father } \\
\hline Illiterate & $236(24.9)$ & $246(26.7)$ & $482(25.8)$ & \multirow[t]{5}{*}{0.011} \\
\hline Primary & $220(23.2)$ & $166(18.0)$ & $386(20.7)$ & \\
\hline Intermediate & $152(16.1)$ & $144(15.6)$ & $296(15.8)$ & \\
\hline Secondary & $164(17.3)$ & $206(22.3)$ & $370(19.8)$ & \\
\hline University and above & $175(18.5)$ & $160(17.4)$ & 335 (17.9) & \\
\hline \multicolumn{5}{|c|}{ Socio-economic status/income } \\
\hline$<1,370$ USD & $138(14.6)$ & $217(23.5)$ & $355(19.0)$ & \multirow[t]{3}{*}{$<0.001$} \\
\hline $1,370-2,740$ USD & $484(51.1)$ & $462(50.1)$ & $946(50.6)$ & \\
\hline$>2,740$ USD & $325(34.3)$ & $243(26.4)$ & $568(30.4)$ & \\
\hline
\end{tabular}

Figures in parentheses are percentages.

necessarily imply diagnostic status. However, the CTRS has been widely used in different cultures for the detection of $\mathrm{ADH}$ symptoms in the general population. This study is a preliminary step to assess the existence of $\mathrm{ADH}$ symptoms in the community and then to conduct a largescale study to evaluate the prevalence of ADH using diagnostic interviews in the future.

$\mathrm{ADH}$ is a chronic disorder which may impact upon many aspects of an individual's life including academic performance, social skill problems and parent-child relationship [7]. The causes of $\mathrm{ADH}$ are not entirely clear; it is believed that the disorder is caused by biological factors [17]. The children with ADH normally have two problem areas: academic performance and achievement [18], consistent with the findings of our study.

Our finding that more children in the age group of $6-9$ years $(13.9 \%)$ had a high score $(\geq 15)$ for ADH symptoms than in that of $10-12$ years $(9.2 \%)$ is similar to the 
Table 2. Prevalence of ADH symptoms among the studied subjects by sociodemographic characteristics and school performance

\begin{tabular}{|c|c|c|c|c|}
\hline Variables & $\begin{array}{l}\text { Mild } \\
\text { (score 0-9; } \\
\mathrm{n}=1,434 \text { ) }\end{array}$ & $\begin{array}{l}\text { Moderate } \\
\text { (score } 10-14 ; \\
\mathrm{n}=227 \text { ) }\end{array}$ & $\begin{array}{l}\text { High } \\
\text { (score } \geq 15 ; \\
n=208 \text { ) }\end{array}$ & $\begin{array}{l}\mathrm{p} \\
\text { value }\end{array}$ \\
\hline \multicolumn{5}{|l|}{ Age group } \\
\hline $6-9$ years & $525(68.9)$ & $131(17.2)$ & $106(13.9)$ & \multirow[t]{2}{*}{$<0.00$} \\
\hline $10-12$ years & $909(82.1)$ & $96(8.7)$ & $102(9.2)$ & \\
\hline \multicolumn{5}{|l|}{ Gender } \\
\hline Boys & $632(66.7)$ & $157(16.6)$ & $158(16.7)$ & \multirow[t]{2}{*}{$<0.00$} \\
\hline Girls & $802(87.0)$ & $70(7.6)$ & $50(5.4)$ & \\
\hline \multicolumn{5}{|l|}{ Nationality } \\
\hline Qatari & $898(78.9)$ & $128(11.2)$ & $112(9.8)$ & \multirow[t]{2}{*}{0.018} \\
\hline Non-Qatari/Arabs & $536(73.3)$ & $99(13.5)$ & $96(13.1)$ & \\
\hline \multicolumn{5}{|l|}{ Consanguinity } \\
\hline Yes & $633(73.5)$ & $118(13.7)$ & $110(12.8)$ & \multirow[t]{2}{*}{0.010} \\
\hline No & $801(79.5)$ & $109(10.8)$ & $98(9.7)$ & \\
\hline \multicolumn{5}{|c|}{ Socio-economic status/income, USD } \\
\hline$>2,740$ & $288(81.1)$ & $38(10.7)$ & $29(8.2)$ & \multirow[t]{3}{*}{0.04} \\
\hline $1,370-2,740$ & $732(77.4)$ & $112(11.8)$ & $102(10.8)$ & \\
\hline$<1,370$ & $414(72.9)$ & $77(13.6)$ & $77(13.6)$ & \\
\hline \multicolumn{5}{|l|}{ Number of children } \\
\hline$<5$ & $571(73.7)$ & $97(12.5)$ & $107(13.8)$ & \multirow[t]{3}{*}{0.028} \\
\hline $5-8$ & $754(78.8)$ & $115(12.0)$ & $91(9.5)$ & \\
\hline$>8$ & $109(81.3)$ & $15(11.2)$ & $10(7.5)$ & \\
\hline \multicolumn{5}{|l|}{ Multiple marriages } \\
\hline Yes & $216(74.7)$ & $31(10.7)$ & $42(14.5)$ & \multirow[t]{2}{*}{0.116} \\
\hline No & $1,218(77.1)$ & $196(12.4)$ & $166(10.5)$ & \\
\hline \multicolumn{5}{|c|}{ Good relationship between parents } \\
\hline Yes & $1,401(80.3)$ & $194(11.1)$ & $149(8.5)$ & \multirow[t]{2}{*}{$<0.00$} \\
\hline No & $33(26.4)$ & $33(26.4)$ & $59(47.2)$ & \\
\hline \multicolumn{5}{|l|}{ Parents living together } \\
\hline Yes & $1,328(77.3)$ & $206(12.0)$ & $185(10.8)$ & \multirow[t]{2}{*}{0.147} \\
\hline No & $106(70.7)$ & $21(14.0)$ & $23(15.3)$ & \\
\hline \multicolumn{5}{|c|}{ Performance at school } \\
\hline Excellent & $280(79.1)$ & $44(12.4)$ & $31(8.5)$ & \multirow[t]{5}{*}{0.002} \\
\hline Very good & $452(77.7)$ & $64(11.0)$ & $66(11.3)$ & \\
\hline Good & $313(74.3)$ & $56(13.3)$ & $52(12.4)$ & \\
\hline Average & $125(69.4)$ & $20(11.1)$ & 35 (19.4) & \\
\hline Below average & $118(62.4)$ & $26(13.8)$ & $45(23.8)$ & \\
\hline
\end{tabular}

Figures in parentheses are percentages.
Table 3. Comparison of the behaviour of the studied children with and without $\mathrm{ADH}$ symptoms

\begin{tabular}{|c|c|c|c|c|}
\hline Variables & $\begin{array}{l}\mathrm{ADH} \\
(\text { score } \geq 15 ; \\
\mathrm{n}=208)\end{array}$ & $\begin{array}{l}\text { No } \mathrm{ADH} \\
\text { (score }<15 \\
\mathrm{n}=1,661)\end{array}$ & $\begin{array}{l}\text { Total } \\
(\mathrm{n}=1,869)\end{array}$ & $\begin{array}{l}\mathrm{p} \\
\text { value }\end{array}$ \\
\hline \multicolumn{5}{|c|}{ Disobedient } \\
\hline Yes & $200(13.5)$ & $1,286(86.5)$ & $1,486(100)$ & \multirow[t]{2}{*}{0.002} \\
\hline No & $8(2.1)$ & $375(97.9)$ & $383(100)$ & \\
\hline \multicolumn{5}{|c|}{ Noisy/hyperactive } \\
\hline Yes & $126(12.8)$ & $856(87.2)$ & $982(100)$ & \multirow[t]{2}{*}{0.014} \\
\hline No & $82(9.2)$ & $805(90.8)$ & $887(100)$ & \\
\hline \multicolumn{5}{|l|}{ Cranky } \\
\hline Yes & $76(11.7)$ & $571(88.3)$ & $647(100)$ & \multirow[t]{2}{*}{0.014} \\
\hline No & $132(10.8)$ & $1,090(89.2)$ & $1,222(100)$ & \\
\hline \multicolumn{5}{|c|}{ Troublesome } \\
\hline Yes & $78(12.9)$ & $526(87.1)$ & $604(100)$ & \multirow[t]{2}{*}{0.119} \\
\hline No & $130(10.3)$ & $1,135(89.7)$ & $1,265(100)$ & \\
\hline \multicolumn{5}{|l|}{ Nervous } \\
\hline Yes & $79(13.1)$ & $526(86.9)$ & $605(100)$ & \multirow[t]{2}{*}{0.147} \\
\hline No & $129(10.2)$ & $1,135(89.8)$ & $1,264(100)$ & \\
\hline \multicolumn{5}{|c|}{ Any children like their teachers } \\
\hline Yes & $105(11.0)$ & $851(89.0)$ & $956(100)$ & \multirow[t]{2}{*}{0.139} \\
\hline No & $103(11.3)$ & $810(88.7)$ & $913(100)$ & \\
\hline
\end{tabular}

Figures in parentheses are percentages.

Table 4. Logistic regression analysis to assess predictors for $\mathrm{ADH}$ disorder

\begin{tabular}{lccc}
\hline Independent variables & Odds ratio & $95 \% \mathrm{CI}$ & $\mathrm{p}$ value \\
\hline Socio-economic condition & 1.713 & $1.24-2.37$ & 0.001 \\
Number of children & 1.128 & $1.04-1.21$ & 0.017 \\
Poor relationship between parents & 10.580 & $6.940-16.129$ & $<0.001$ \\
School performance & 1.253 & $1.071-1.467$ & 0.005 \\
Occupation of father & 0.964 & $0.858-1.083$ & 0.538 \\
Occupation of mother & 1.043 & $0.885-1.228$ & 0.617 \\
Education of father & 1.061 & $0.914-1.230$ & 0.437 \\
Education of mother & 1.003 & $0.859-1.171$ & 0.971 \\
Parity & 0.983 & $0.905-1.067$ & 0.679 \\
Consanguinity & 0.755 & $0.554-1.029$ & 0.075 \\
\hline
\end{tabular}

findings of Sharma et al. [19]. Equally, the finding that more boys than girls (3:1) had this disorder is consistent with a previous report [20].

The first-cousin intermarriage rate in Qatar is 34.8\% [5], which was suspected to be related to the high prevalence rate of $\mathrm{ADH}$ in children (11.1\%), but logistic regression analysis did not yield a significant association between consanguinity and ADH in children. However, the present study did find an association between $\mathrm{ADH}$ symptoms and both educational difficulties and school performance of the child. Children who had higher scores for ADH symptoms were judged by teachers as having a poorer performance than those with lower scores. These findings are consistent with other studies from different parts of the world applying behaviour ratings by parents and teachers [1]. 
Moreover, there was a significant difference between children with and without ADH for disobedience, making noise and crying for anything. $96.2 \%$ of the studied children with ADH were disobedient, and $60.6 \%$ were noisy and hyperactive. Children with ADH have difficulty paying attention and controlling their behaviour. These results are consistent with previous reports. White [21] found that children with unusually high activity and emotional reactivity may be more distractible and more impulsive and that they are frequently diagnosed as having $\mathrm{ADH}$. ADH increases the risk of additional problems such as conduct and personality disorders, substance misuse, offending and impaired social adjustment in adulthood [22].

The logistic regression in our study showed that a poor relationship between parents and socio-economic condition were the main contributors for $\mathrm{ADH}$. The poor parenting practices and other family environmental variables affect the children with $\mathrm{ADH}$. In fact, generally children whose parents are divorced or not in a favourable relationship do not get proper attention and care from their parents, and this leads to a higher incidence of $\mathrm{ADH}$ symptoms $[23,24]$. In a study conducted in the United Arab Emirates [13], there was a significant association between a higher score of ADH symptoms and children being raised by a single parent. The results of a study done in Israel suggest that children with $\mathrm{ADH}$, who have a difficult temperament and difficulties in self-regulation, need supportive and organizing parenting which provides a lower incidence of ADH symptoms [25].

\section{Conclusion}

The present study revealed that $\mathrm{ADH}$ is found to be a common problem among schoolchildren. A significant difference in the behaviour reported by parents was found between children with and without ADH symptoms. The children with higher scores for $\mathrm{ADH}$ symptoms had a poorer school performance than those with lower scores. A poor relationship between parents was the main contributor to ADH in children.

\section{Acknowledgements}

The study was supported by Hamad Medical Corporation Project No. 320-2005. The authors would like to thank the teachers, staff of schools and Mrs. Soji Samson for their help in this study. Also, they express their sincere thanks to the reviewer who gave valuable comments to improve the presentation of the paper.

\section{References}

1 Barbaresi WJ, Katusic SK, Colligan RC, Pankratz VS, Weaver AL, Weber KJ, Mrazek DA, Jacobsen SJ: How common is attention deficit/hyperactivity disorder? Incidence in a population-based birth cohort in Rochester, Minnesota. Arch Pediatr Adolesc Med 2002; 156:217-224.

2 Purper OD, Wohl M, Michel G, Moureh MC, Gorwood P: Symptom variations in ADHD: importance of context, development and comorbidity. Encéphale 2004;30:533-539.

3 Barkley RA: Child behaviour rating scales and checklists; in Rutter M, Tuma AH, Lann IS (eds): Assessment and Diagnosis in Child Psychopathology. New York, Guilford Press, 1988, pp 113-155.

4 Sayal K, Hornsey H, Warren S, Macdiarmid F, Taylor E: Identification of children at risk of attention deficit/hyperactivity disorder, a school based intervention. Soc Psychiatry Epidemiol 2006;41:806-813.

5 Bener A, Alali KA: Consanguineous marriages in the new developed country: Qatari population. J Biosoc Sci 2006;38:239-246.
6 Faraone SV, Biederman J, Spencer T, Wilens T, Seidman LJ, Mick E, Doyle AE: Attention deficit/hyperactivity disorder in adults: an overview. Biol Psychiatry 2000;48:9-20.

7 Weiss G, Hechitman L: Hyperactive Children Grown Up: ADHD in Children, Adolescents and Adults. New York, Guilford Press, 1993.

-8 Bener A, Al-Qahtani R, Abdelaal I: The prevalence of ADHD among primary schoolchildren in an Arabian Society. J Atten Disord 2006;10:77-82.

-9 Maniadaki K, Sonuga-Barke E, Kakouros E, Karaba R: Parental beliefs about the nature of ADHD behaviours and their relationship to referral intentions in preschool children. Child Care Health Dev 2007;33:188-195.

10 Taylor E, Sandberg S, Thorley G, Giles S: The Epidemiology of Childhood Hyperactivity. Oxford, Oxford University Press, 1991, pp 4-143.

11 Johnson BD, Franklin LC, Hall K, Prieto LR: Parent training through play: parent child interaction therapy with a hyperactive child. Family J 2000;8:180-186.
12 Luk SL, Leung PW: Conners' Teacher's Rating Scale - a validity study in Hong Kong. J Child Psychol Psychiatry 1989;30:785-793.

13 Bu-Haroon A, Eapen V, Bener A: The prevalence of hyperactivity symptoms in the United Arab Emirates. Nordic J Psychiatry 1999; 53:439-442.

14 Goyette CH, Conners CK, Ulrich RF: Normative data on revised Conners parent and teacher rating scales. J Abnorm Child Psychol 1978;6:221-236.

15 Miller LS, Koplewicz HS, Idein RG: Teacher ratings of hyperactivity, inattention and conduct problems in preschoolers. J Abnorm Child Psychol 1997;25:113-119.

16 Rowland AS, Umbach DM, Catoe KE, Stallone L, Long S, Rabiner D, Naftel AJ, Panke D, Faulk R, Sandler DP: Studying the epidemiology of attention-deficit hyperactivity disorder: screening method and pilot results. Can J Psychiatry 2001;46:931-940.

17 Barkley RA: Attention Deficit Hyperactivity Disorder: A Handbook for Diagnosis and Treatment, ed 2. New York, Guilford Press, 1998. 
18 Faraone SV, Biederman J, Monuteaux MC: A psychometric measure of learning disability predicts educational failure 4 years later in boys with ADHD. J Atten Dis 2001;4:220230.

19 Sharma V, Newcorn J, Schulz K, Halperin J: Childhood disorders: attention deficit and disruptive behaviour disorders; in Tasman A, Kay J, Lieberman J (eds): Psychiatry, ed 2. Chichester, John Wiley \& Sons, 2003, pp 779-798.
20 Child Development Institute Research Center: About attention deficit hyperactivity disorder (2005). http://www.childdevelopmentinfo.com/disorders/adhd.shtml (accessed May 21, 2007).

21 White JD: Personality, temperament and ADHD: a review of the literature. Pers Individ Diff 1999;27:589-598.

22 Sayal K, Goodman R, Ford T: Barriers to the identification of children with attention deficit/hyperactivity disorder. J Child Psychol Psychiatry 2006;47:744-750.
23 Stein MT, Diller L, Resnikoff R: ADHD, divorce, and parental disagreement about the diagnosis and treatment. J Dev Behav Pediatr 2001;22:61-65.

24 Eapen V, Al-Sabosy M, Saeed M, Sabri S: Child psychiatric disorders in a primary care Arab population. Int J Psychiatry Med 2004; 34:51-60.

25 Finzi-Dottan R, Manor I, Tyano S: ADHD, temperament, and parental style as predictors of the child's attachment patterns. Child Psychiatry Hum Dev 2006;37:103-114. 